\section{THU0157 CARTILAGE OLIGOMERIC MATRIX PROTEIN (COMP) AND SOLUBLE CD44 VARIANT ISOFORM V5 (SCD44V5) IN PATIENTS WITH EROSIVE, SEROPOSITIVE RHEUMATOID ARTHRITIS (RA+)}

1) Feyertag, ${ }^{1} \mathrm{G}$ Haberhauer, ${ }^{2} \mathrm{M}$ Skoumal, ${ }^{3} \mathrm{EM}$ Kittl, ${ }^{3} \mathrm{~K}$ Bauer, ${ }^{1} \mathrm{~A}$ Dunky. ${ }^{1} 5$ th Department of Internal Medicine (Rheumatology), Wilhelminen Hospital; ${ }^{2}$ Institute for Rheumatology, Baden, Austria; ${ }^{3}$ Central-Laboratory, Danube-Hospital, Vienna

10.1136/annrheumdis-2001.1059

Background “*”

Objectives COMP is a pentameric protein of five identical disulfide-linked subunits and belongs to the thrombospondin family of proteins. It is proposed to be a marker of cartilage degradation and may be correlated to disease activity with respect to joint destruction in patients with $\mathrm{RA}+$ and osteo-arthritis. The concentration of COMP in serum may decrease due to effective treatment of RA+.

sCD44v5 has been described in patients with erosive RA+ and in patients with (longstanding) psoriatic arthtitis. It has been proposed to be a (slow acting) marker of disease activity and disease prognosis. The influence of different therapeutic procedures on sCD44v5 serum levels has been described. We were searching for correlations of sCD44v5 and COMP in the course of disease of patients with erosive RA.

Methods Serum levels of COMP and sCD44v5 were measured in 53 patients with RA+ (Steinbrocker stages II-IV, duration of disease $>2$ years). Follow up measurements were performed 8 times always after 3 months. Additionally routine laboratory monitoring and clinical assessment of the disease status were performed. ELISA-tests were used to detect COMP- and sCD44v5serum levels.

Results In our 53 patients with RA+ we could find significant correlations of COMP and sCD44v5 ( $p<0,0001$ ), of COMP and rheumatoid factor measurements (RF) ( $p<0,006)$, of sCD44v5 and RF ( $p<0,0001)$, of sCD44v5 and erythrocyte sedimentation rate (ESR) $(\mathrm{p}<0,003)$, and of $\mathrm{sCD} 44 \mathrm{v} 5$ and (a modified) Ritchie-Index ( $\mathrm{p}=0,05)$.

Conclusion To interpret the implications of our preliminary results with reference to disease activity, cartilage destruction, disease progression and prognosis under different therapeutic procedures in patients with $\mathrm{RA}+$, further studies are necessary.

(Supported by “Vienna Bürgermeister-Fond” No.1452).

\section{REFERENCES}

“*”

\section{THU0158 WORK DISABILITY AMONG PATIENTS WITH RHEUMATOID ARTHRITIS IN LITHUANIA}

${ }^{1} \mathrm{JH}$ Dadoniene, ${ }^{2} \mathrm{~A}$ Boonen. ${ }^{1}$ The Clinic of Internal Medicine and Rheumatology, Vilnius University, Vilnius, Lithuania; ${ }^{2}$ Department of Rheumatology, University Hospital Maastricht, Maastricht, Netherlands

\subsection{6/annrheumdis-2001.1060}

Background Work disability is increasingly recognised as an important outcome of rheumatoid arthritis (RA). The magnitude of work-disability in chronic disease is not only determined by socio-economic and disease characteristics but also by the organisation of the social security system of the country under study. Objectives To determine the work disability levels of Lithuanian patients with RA.
Methods A cross-sectional study was performed including 276 consecutive out-patients, registered in the Vilnius RA register. During structured interviews, patients were asked about sociodemographic (including work-status) and disease characteristics. In addition, patients underwent a physical examination. The social security system in Lithuania distinguishes short-term disability (maximum 4 month) and long standing (permanent) disability. In case of longstanding disability three categories can be granted and two of these allow continuing a job.

Results Of the 276 RA patients, 82.2\% were female, mean age was $58.9 \mathrm{yr}(\mathrm{SD}=11.8)$ and mean disease duration $11.9 \mathrm{yr}$ (SD =9.4). Of 183 patients in working age (14-65 yr), 3.3\% were unemployed or housewife, $7,1 \%$ were on early retirement and after adjusting for age and gender $28.3 \%$ had a paid job and $45.8 \%$ had a disability allowance. In general population of Lithuania employment rate is $54.5 \%$ and disability rate $2.33 \%$. Of those with paid job $34.5 \%$ were holding at the same time a disability allowance. The Table 1 contrasts demographic and disease characteristics of those having a job to those having no job.

\begin{tabular}{lll} 
Abstract THU0158 Table 1 & & \\
\hline & $\begin{array}{l}\text { Employed } \\
\mathbf{n}=58\end{array}$ & $\begin{array}{l}\text { Not } \\
\text { employed } \\
\mathbf{n}=125\end{array}$ \\
\hline Female; $\mathrm{nr}(\%)$ & $49(84.5)$ & $102(81.6)$ \\
Age; yr (SD) & $47.6(8.7)$ & $54.8(8.2)^{*}$ \\
Disease duration; yr & $9.2(8.7)$ & $13.2(9.1)^{*}$ \\
(SD) & & $11.9(3.6)^{*}$ \\
Education; yr (SD) & $14.4(3.1)$ & $5.5(1.1)$ \\
DAS-28; mean (SD) & $5.3(1.1)$ & $1.5(0.7)^{*}$ \\
MHAQ (0-3; mean (SD)) & $0.8(0.6)$ & \\
\hline *t-test for continuos values and chi-square for proportions and significance level $<0.05$.
\end{tabular}

Conclusion In Lithuania, employment among RA patients is $26.2 \%$ lower than in the general population and seems lower than reported in literature on labour force participation among RA patients in other countries. Not suprisingly, patients who are more educated, less diabled and have shorter disease duration are more likely to remain in labour force, though disease activity is similar to those being not employed.

\section{THU0159 PERIPROSTHETIC BONE REMODELLING AND RADIOGRAPHIC FIXATION OF A CEMENTLESS TOTAL HIP ARTHROPLASTY WITH TITANIUM STEM IN RHEUMATOID ARTHRITIS AND OSTEOARTHRITIS PATIENTS}

T Taketa, H Ohnishi, H Turukami, N Okimoto, M Takeda, S Okabe, T Nakamura. Orthopedics Surgery, University of Occup. and Environ. Health, Kitakyushu, Japan

\subsection{6/annrheumdis-2001.1061}

Background New bone formation around cement less stem after total hip arthroplasty is dependent on implant design, material, and mode of porous coating. These osteogenesis patterns are classified as follows, proximal endosteal bone bridging spot welds, increased cortical thickness (cortical hypertrophy) and thin radiodense lines surrounding the tip of the implant (halo pedestal). However, no reports showed the comparison of bone remodelling patterns surrounding stem among diseases: such as 
osteoarthritis (OA), rheumatoid arthritis (RA), avascular necrosis and neck fracture.

Objectives The purpose of this study is to clarify whether there are differences of the postoperative bone remodelling pattern around the femoral stem between RA and OA patients.

Methods Total hip arthroplasty with the Mallory-Head cement less titanium prosthesis has been performed since 1992 in our institute. This tapered stem has plasma spray coating in proximal one third of it. RA group included 18 hips (mean age at operation was fifty-five years old and mean duration of follow-up was 4.6 years). OA group included 70 hips (mean age at operation was fifty-eight years old and mean duration of follow-up was 5.2 years). Anteroposterior radiographs of the hip were made at 6 weeks, 3 months, 6 months, one year and every year after the operation. We evaluated the frequency and time of new bone remodelling appearance around the stem such as spot welds, cortical hypertrophy, and pedestal. We defined that the radiographic signs of instability were progressive subsidence or the presence of radiolucent lines around the porous coating. ${ }^{1}$ To evaluate the differences in both groups, the Mann-Whitney's U test and chi-square test were used. $\mathrm{P}$ values of less than 0.01 ? @were considered significant.

Results In both groups, there was no case, which has radiographic sign of instability. Age and intramedurally canal fill of the stem at the operation and follow-up period were not significantly different between RA and OA groups. In endosteal spot welds, the time of its appearance in RA group (2.7 months after operation) was significantly shorter than that in OA group (5.2 months) and the frequency of it did not differ between both groups. However, in halo pedestal, the frequency in RA group $(50 \%)$ was significantly lower than that in OA group (87\%) and the time of its appearance did not differ between both groups. On the other hand, concerning about cortical hypertrophy, time and frequency showed no significant differences between two groups.

Conclusion We revealed that in RA patients, endosteal spot welds appeared significantly earlier than that in OA patients, and the frequency of halo pedestal was significantly lower than that in OA patients.

\section{REFERENCE}

1 Mulliken $\mathrm{BD}$, Bourne $\mathrm{RB}$, Rorabeck $\mathrm{CH}$, et al. A tapered titanium femoral stem inserted without cement in a total hip arthroplasty. J Bone Joint Surg Am. 1996;78:1214

\section{THU0160 SEMI-QUANTITATIVE AND STANDARDISED SONOGRAPHIC INVESTIGATIONS OF THE ACTIVITY OF INFLAMATION IN PATIENTS WITH RHEUMATOID ARTHRITIS}

${ }^{1} \mathrm{C}$ Weidekamm, ${ }^{1} \mathrm{~F}$ Kainberger, ${ }^{2} \mathrm{M}$ Koeller, ${ }^{2} \mathrm{~L}$ Erlacher, ${ }^{1} \mathrm{H}$ Imhof. ${ }^{1}$ Department of Diagnostic Radiology; ${ }^{2}$ Department of Rheumatology, University-Hospital AKH-Vienna, 1020 Wien, Austria

\subsection{6/annrheumdis-2001.1062}

Background With high-resolution sonography (US) of joints affected by rheumatoid arthritis (RA) a detailed delineation of intra- and extraarticular soft-tissue abnormalities is possible. Power-Doppler is useful for the analysis of the vascularisation of inflamed tissue. The aim of the study was to evaluate the diagnostic value of Power-Doppler and B-Mode US in context with clinical examinations and conventional radiography.

Objectives
Methods To date, in 22 patients (5 males, 17 females) with different grades of RA (17 RF+, 5RF-) the wrists and MCP I-V and PIP II-V were scored with sonography (ATL HDI 5000, $5 \square 12$ $\mathrm{MHz}$ Transducer, synthetic plastic blocks) with B-Mode and Power-Doppler application in standardised technique. Extension and severity of the inflamed tissue as well as vascularisation were scored. The results were correlated with benchmarks of the clinical and radiologic investigations. Radiographs were assessed according to the Larsen Score. The amount of time of US investigation was measured.

Results With sonography, both extension and severity of wrist lesions could be delineated to better advantage than with radiography and clinical examination. This was also true for the MCP joints with the exception of MCP II, where most of the lesions detected by radiography were found. From 484 joints, 29\% were found to be abnormal by clinical investigations. Erosions were detected in $26 \%$ with radiography, in $37 \%$ with sonography. Hypervascularisation was found in $36 \%$. No significant difference of US abnormalities between patient groups with positive and negative RF could be found. A modern state-of-theart Power Doppler program release is a necessary tool for semiquantification. A standardised investigation technique with a median amount of time of 18 min provides sufficient quality measures.

Conclusion Sonography detects more bone erosions than radiography and clinical examination. It supports the diagnosis of RA manifestations of the hand.

\section{REFERENCES}

1 Fitzgerald O, Bresnihan B. Synovial vascularity is increased in rheumatoid arthritis: comment on the article by Stevens, et al.[letter]. Arthritis Rheum. 1992;35:154041

2 Hau M, Schultz H, Tony HP, Keberle M, Jahns R, Haerten R, Jenett M. Evaluation of pannus and vascularization of the metacarpophalangeal and proximal interphalangeal joints in rheumatoid arthritis by high-resolution ultrasound (multidimensional linear array). Arthritis Rheum. 1999;42(11):2303-8

3 Grassi W, Tittarelli E, Pirani O, Avaltroni D, Cervini C. Ultrasound examination of metacarpophalangeal joints in rheumatoid arthritis. Scand I Rheumatol. 1993;22:243-7

\section{THU0161 RHEUMATOID ARTHRITIS WITH ANTIKERATIN ANTIBODIES (AKA): A DISTINCT IMMUNOGENETIC OR PROGNOSTIC SUBGROUP?}

${ }^{1} \mathrm{~A}$ Gómez, ${ }^{1} \mathrm{R}$ Sanmartí, ${ }^{2} \mathrm{O}$ Viñas, ${ }^{2} \mathrm{G}$ Ercilla, ${ }^{1} \mathrm{JD}$ Cañete, ${ }^{1} \mathrm{C}$ Orellana, ${ }^{1} \mathrm{G}$ Salvador, 'J Muñoz-Gómez. ${ }^{1}$ Rheumatology; ${ }^{2}$ Immunology, Hospital Clinic, Barcelona, Spain

10.1136/annrheumdis-2001.1063

Background Antikeratin antibodies (AKA) have been described as the most specific serologic markers of RA. However, whether these antibodies can identify a particular RA population it remains controversial.

Objectives To compare the immunogenetic features (HLA-DRB1 and TNF-a polymorphism) and radiological severity of a group of patients with early RA, according to the presence or not of AKA.

Methods 65 patients with early RA (48F/17M, mean age: $50 \pm$ $14 \mathrm{y}$, mean disease duration $15 \pm 12 \mathrm{mo}, \mathrm{RF}+: 71 \%)$ were genotyped for HLA-DRB1 and TNF-a alleles. Hands and feet $\mathrm{x}$-ray were taken at entry and then yearly during follow-up. The Larsen method was used to assess radiographic damage. AKA was determined by immunofluorescence using a modified Young method (sensitivity/specificity 60.2\%/98.3\%).

Results AKA were present in the sera of 34 patients (prevalence of $52.3 \%$ ). RF was more frequently found in AKA+ patients 